\title{
Correlation between shear wave velocity and effective confining pressure using cyclic triaxial testing apparatus
}

\author{
Guojun Liu, ${ }^{1, *}$, Noriyuki Yasufuku${ }^{1}$, Ryohei Ishikura ${ }^{1}$, and Qiang Liu ${ }^{2}$
}

${ }^{1}$ Kyushu University, Department of Civil and Structural Engineering, Fukuoka, Japan

${ }^{2}$ Shandong University of Science and Technology, College of Earth Science and Engineering, P.R.China

\begin{abstract}
The 2016 Kumamoto earthquakes struck Kumamoto and Ōita regions and caused several devastating liquefaction induced damages. The primary damage was due to the extreme ground shaking of the foreshock and main shock sequence. Therefore, it is essential to develop a quick reliable approach with a high accuracy to assess the ground situation after foreshock or several shocks. Velocity of small shear wave (Vs) was widely used for evaluating the potential liquefaction. This study investigates the possibility of using Vs as a new indicator of the stress state in the soil after earthquake and evaluation of post liquefaction resistance of soil. Cyclic tri-axial apparatus equipped with bender elements were used to conduct two consecutives liquefaction tests on sandy soil. The Vs measured by bender elements was discussed on the relationship with effective stress during the liquefying processes. The results showed that for the sandy soils, a) Vs could not clearly reflect the significant reduction in resistance at re-liquefaction stages by directly comparing the Vs at the end of consolidation between first and stages, b) The shear wave velocity is significantly affected by effective confining pressure c) the shear wave velocity of $190 \mathrm{~m} / \mathrm{s}$ was at confining pressure of $100 \mathrm{kPa}$. The shear wave velocity reaches to after $100 \mathrm{~m} / \mathrm{s}$ after consolidations and re-consolidations. The shear wave velocity was found to reduce to $100 \mathrm{~m} / \mathrm{s}$ when the effective confining stress reaches to 0 and to around $25 \mathrm{~m} / \mathrm{s}$ when the double amplitude reaches to $5 \%$; d) the velocity and effective stress decreases with a similar rate in liquefying process.
\end{abstract}

\section{Introduction}

In recent years, many earthquakes induced geo-disasters are reported after extreme events such as the 2011 Tohoku Great earthquakes and the 2016 Kumamoto Earthquakes in Japan. Soil liquefaction induced damage played an important role in these disasters considering the special geological conditions of Japan. Fig. 1 shows the earthquake acceleration of two great shocks appeared in the 2016 Kumamoto Earthquakes [1]. Recorded data at Mashiki town which were collected at the location very close to the epicentres showed that the two great shocks struck there within a very short time interval as foreshock (M6.5) struck there on April 14 $4^{\text {th }}$, and about 28 hours later, the main shock (M7.3) hit the same region again in the middle night on April $16^{\text {th }}$.

According to the field investigation conducted right after the earthquakes, the two major shocks were the main reason for the extreme liquefaction induced damage. Many sites were found to not affected by liquefaction or damaged very slightly during foreshock, however, these sites were destroyed or badly damaged by soil liquefaction in mainshock, which was beyond prediction by a same magnitude as the mainshock in the 2016 Kumamoto earthquakes. [2] This kind of damage appeared not only the at Mashiki town and the vicinity, but also at almost of entire of Kumamoto plain and Aso basin. A lot of buildings' foundations, embankments, farmlands damaged and even some landslides on the hills with a gentle gradient were observed that was directly or potentially collapsed by soil liquefaction.

Concerns on the liquefaction are in correlation with multiple liquefaction stages, some previous researchers attempted to provide the portable reasons. It is widely believed that the generated excess pore water pressure remained in the ground when next shock struck. Researchers reported that for the completely drained cases, anisotropy induced in samples at the end of each stage were assumed to be the main reason. K. Ishihara et. al. [36] found that the variation was mainly affected by the stress history in previous stage of loading by the cyclic triaxial tests. They defined the line of phase transition which makes the boundary with failure line. If the shear stress placed in between the boundaries in the previous stage, the shear stress should be identified as the major pre-shearing for current stage. The liquefaction resistance would decrease significantly in this situation. On the contrary, the small pre-shearing would densify the soil and improve the liquefaction resistance.

Table 1. Physical properties of Toyoura sand

\begin{tabular}{cc}
\hline Specific gravity & 2.643 \\
Maximum void rate $\boldsymbol{e}_{\max }$ & 0.977 \\
Minimum void rate $\boldsymbol{e}_{\min }$ & 0.606 \\
\hline
\end{tabular}

\footnotetext{
* Corresponding author: liuguojunjj0@163.com
} 


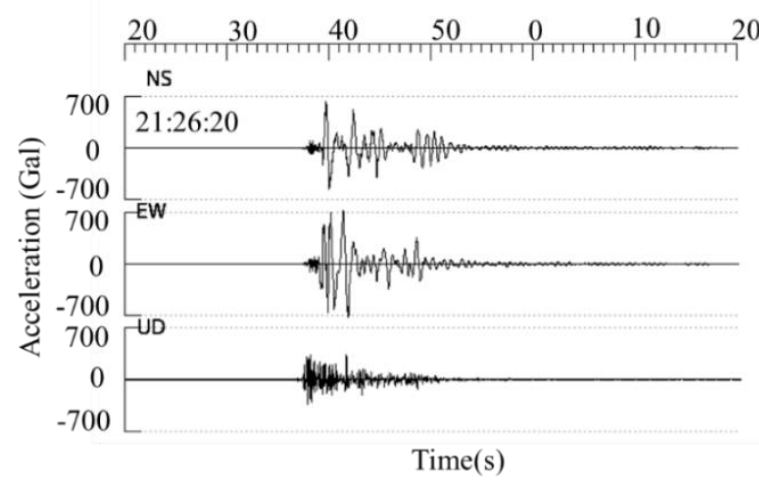

(a) Foreshock on April 14 $4^{\text {th }}$

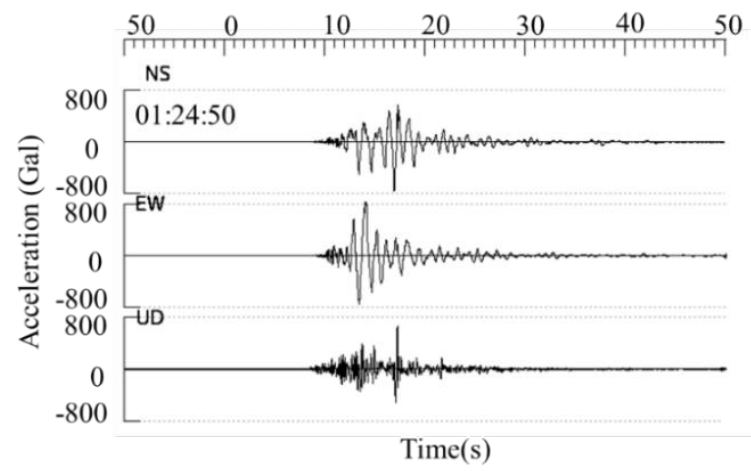

(b) Mainshock on April $16^{\text {th }}$

Fig. 1. Acceleration history measured in Mashiki Town

Some other researchers believe that the anisotropy was also affected by the final load directions in cyclic tests. They figured out that the liquefaction resistance depends on the loading directions between the last direction in previous stage and the direction in current stage [7].

Obviously, in the real disaster scenario, both the anisotropy and the residual excess pore water pressure are important factors. However, the two factors could not be measured directly during the earthquake. On the other hand, the small strain shear wave velocity which is being conducted under small and non-destructive shear wave, is widely utilized for evaluating the variations of soil internal structure in situ investigations after geo- disasters. Velocity of shear wave could be considered as a convenient index for liquefaction resistance, because like liquefaction resistance, it is influenced by some similar factors such as void ratio, state of stress, stress history, and geological age $[8,9]$. This study assessed the possibility of using the shear wave velocity (Vs) to determine the liquefaction potential of post-liquefied soils by discussing the stress states and the probable changed anisotropy.

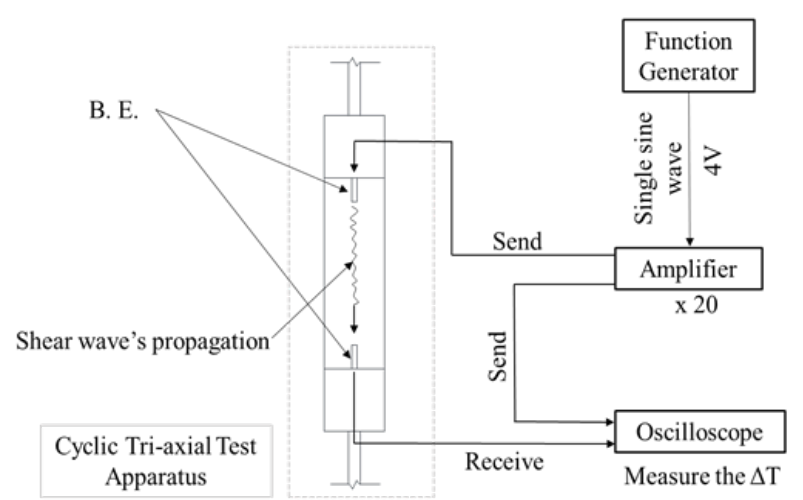

Fig. 2. Illustration of tri-axial cyclic test apparatus with bender elements

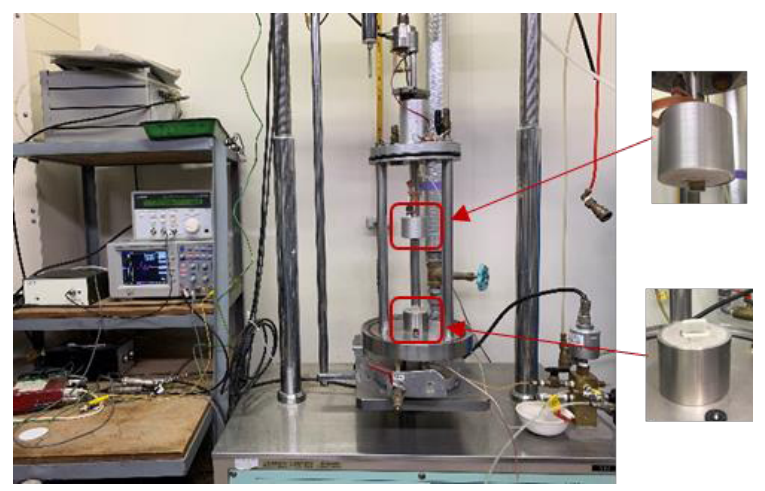

Fig. 3. Photo of tri-axial cyclic test apparatus assembled with bender elements

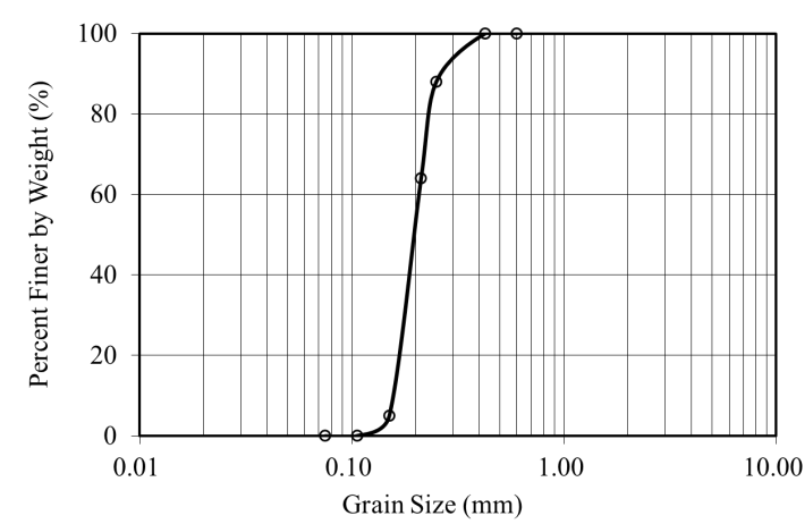

Fig. 4. Cumulative grain size distribution of Toyoura sand

\section{Performance of shear wave velocity in cyclic tri-axial compression tests}

\subsection{Shear wave velocity and liquefaction potential of post liquefied soil}

The correlation between liquefaction potential and Vs investigated by using actual earthquake data or cyclic triaxial tests were conducted by some researchers $[10,11]$. However, there are still lack of way for evaluating presheared cases. Both of how much of excess pore water produced in previous shocks and the recovery state post shocks is unpredictable. Excess pore water pressure is commonly used to indicate the development state of 
Table 2. Dimensional changes of specimens during tests

\begin{tabular}{ccccccc} 
No. & $\boldsymbol{H}_{\boldsymbol{1}}(\mathbf{m m})$ & $\boldsymbol{D}_{\boldsymbol{1}}(\mathbf{m m})$ & $\boldsymbol{H}_{\boldsymbol{u}}(\mathbf{m m})$ & $\boldsymbol{D}_{\boldsymbol{u}}(\mathbf{m m})$ & $\boldsymbol{H}_{2}(\mathbf{m m})$ & $\boldsymbol{D}_{2}(\mathbf{m m})$ \\
\hline C-1 & 99.99 & 51.11 & 99.44 & 51.25 & 99.30 & 50.96 \\
C-2 & 100.04 & 50.99 & 100.06 & 50.99 & 99.96 & 50.69 \\
C-3 & 99.39 & 51.05 & 99.70 & 50.97 & 99.19 & 50.74 \\
C-4 & 101.38 & 51.07 & 100.92 & 51.19 & 100.83 & 50.92 \\
C-5 & 100.05 & 51.16 & 100.01 & 51.18 & 99.91 & 50.89 \\
C-6 & 99.92 & 50.99 & 99.11 & 51.20 & 99.08 & 50.89 \\
\hline
\end{tabular}

Table 3. Conditions of test materials

\begin{tabular}{|c|c|c|c|c|c|c|c|}
\hline & B value & $e_{01}$ & $D r .1(\%)$ & $\sigma_{d} / 2 \sigma_{01}^{\prime}$ & $e_{02}$ & $D r_{2}(\%)$ & $\sigma_{d} / 2 \sigma_{02}^{\prime}$ \\
\hline $\mathrm{C}-1$ & 0.954 & 0.760 & $58.41 \%$ & 0.242 & 0.738 & $64.42 \%$ & 0.244 \\
\hline $\mathrm{C}-2$ & 0.939 & 0.753 & $60.40 \%$ & 0.231 & 0.731 & $66.41 \%$ & 0.231 \\
\hline $\mathrm{C}-3$ & 0.976 & 0.752 & $60.65 \%$ & 0.220 & 0.727 & $67.35 \%$ & 0.219 \\
\hline$C-4$ & 0.961 & 0.734 & $65.53 \%$ & 0.267 & 0.715 & $70.73 \%$ & 0.265 \\
\hline$C-5$ & 0.960 & 0.727 & $67.40 \%$ & 0.252 & 0.706 & $73.06 \%$ & 0.256 \\
\hline C-6 & 0.958 & 0.725 & $67.91 \%$ & 0.243 & 0.704 & $73.60 \%$ & 0.242 \\
\hline
\end{tabular}

liquefaction. Thus, it also could be concluded that liquefaction potential increases gradually accompanied with process of that the accumulated excess pore water pressure gradually replaces the initial effective stress in the previous shock and decreases after the shocks. Therefore, it is worth to assess the applicability of Vs as an indicator of excess pore water pressure development during and after earthquake. For sandy soils in this study, the variation of Vs is affected by the simplified assumptions: a) pore water cannot resist a shear stress b) Suppose that the velocity doesn't affected while propagating through soil particles because of their very small size. Therefore, the Vs would be transferred only by the contact force between soil particles simply. The contact fore presents as the effective confirming stress determined by excess pressure normally.

Therefore, in an ideal case for sandy soils, the velocity has a certain value for natural sediments and soils or remoulded samples in laboratory. Once the soil is disturbed by the cyclic loads, the Vs should decease with the generated pore water pressure until it become zero while the liquefaction is achieved. This kind of correlation was majorly investigated by the experimental tests under cyclic tri-axial compression tests in the study. After that, discuss the performance of Vs between liquefaction and re-liquefaction caused by the potential changes of anisotropy briefly.

\subsection{Cyclic tri-axial compression test assembled with bender elements}

A couple of bender elements and the measurement system for shear wave were assembled on the cyclic tri-axial compression apparatus, shown in Fig. 2 and Fig. 3. A single sinusoidal shear wave is generated from the upper side of the bender element and passes through the soil specimen, finally is received by the lower bender element recorded by the oscilloscope. At the same time, the other

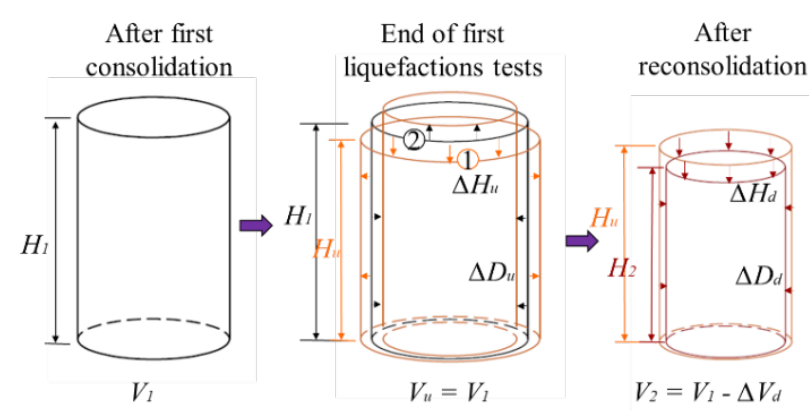

Fig. 5. Deformations of specimens during tests

signal of shear wave was sent directly from the signal generator and it also is received and recorded in oscilloscope. Obviously, the necessary time of the two traveling paths is deferent and it is considered as the travel time $\Delta \mathrm{T}$ of shear wave travelled inside of specimen. The velocity of shear wave could be obtained by the simplified equation according to JGS standard: [12]

$$
V S=\frac{L}{\Delta T}
$$

where, $L$ : the distance between two bender elements, calculated by considering the axial strain variation during the tests; $\Delta T$ : travel time of shear wave in specimen.

Toyoura sand was used as the test material in the experiments. The physical properties are showed in Fig. 4 and Table 1. Cylindrical specimens with $100 \mathrm{~mm}$ in height and $50 \mathrm{~mm}$ in diameter were prepared and tested. Two undrained cyclic triaxial test were conducted to liquefy the soil two times in a row in the study. Fig. 5 shows the deformation of specimens with experiment progress. The height could be increased or decreased based on the recorded data after first liquefaction test without the volume change. The confining pressure in consolidation and re-consolidation was set at $100 \mathrm{kPa}$ and provided an enough drainage time to dissipate the residual excess pore water pressure for evaluating the potential anisotropy. The 
summary of tests conditions is presented at Table 2 and Table 3. The cyclic stress ratio $\sigma_{\mathrm{d}} / 2 \sigma_{0}^{\prime}$ (CSR) was set as a similar degree in first liquefaction test and second liquefaction test. The cyclic axial load was set follow the sinusoidal wave with the frequency of $0.1 \mathrm{~Hz}$. Vs was checked through entire process.

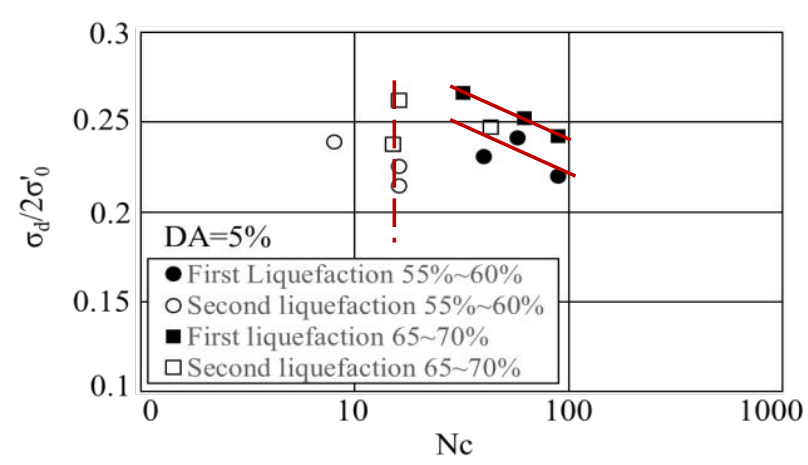

Fig. 6. Comparison for liquefaction strength of sands in first liquefaction and re-liquefaction

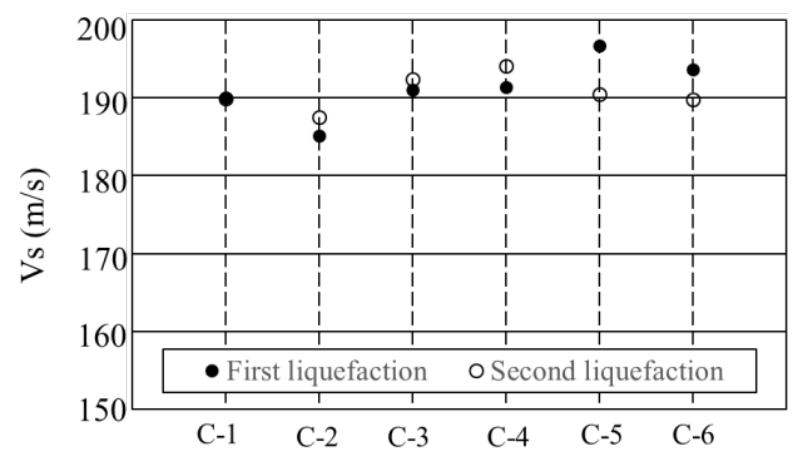

Fig. 7. Shear wave velocity in initial of first liquefaction and second liquefaction stages

\section{Test Results}

\subsection{Performances of Vs correlated with potential anisotropy produced by pre-shearing}

Fig. 6. indicates the liquefaction resistance of sand with different relative densities and CSR. Here, Nc the number of load cycles needed to satisfy both conditions of that excess pore water pressure ratio reached 1.0 and $5 \%$ in double amplitudes (DA. $=5 \%$ ). The results indicate that a) In first liquefaction test, Nc shows a linear relation with CSR in a logarithmic coordinate in each group with the similar relative densities. Contrarily, in second liquefaction tests, regardless of initial relative density, the Nc was found to be around 15 for the samples sheared at second stage until liquefaction is achieved. According to the researches by K. Ishihara et. al, the shear stress should cross the boundary of phase transformation if the soil was liquefied once. Therefore, comparing with the increment about $5 \% \sim 7 \%$ of relative densities as listed in Table 3 , the produced anisotropic deformation could be considered to play important role in determining liquefaction resistance in re-liquefaction stages. However, comparing the initial Vs between first and second stage it could not reveal the correlation between Vs and the variation of anisotropy, as showed in Fig. 7. It could be found that the Vs was recorded around $190 \mathrm{~m} / \mathrm{s}$ regardless loading stages. The Vs was measured after consolidation and re-consolidation with an enough period to remove the influence from residual excess pore water pressure completely.

\subsection{Performances of Vs correlated with effective confining stress.}

Significant variation of excess pore water pressure was recorded during the B-value measurement. Vs was checked in the three steps during this process as shown in Fig. 8. The total confining pressure was increased form 20 $\mathrm{kPa}$ to $100 \mathrm{kPa}$. First Vs was measured before applying the confining pressure. Then check it after confining pressure applying but kept closing the outlet to retain the produced pore water pressure. Finally, checked the Vs after the release of excess pore water pressure. Results indicated that the Vs was significantly affected by the level of confining pressure. In the first step, the Vs was recorded at around $130 \mathrm{~m} / \mathrm{s} \sim 140 \mathrm{~m} / \mathrm{s}$ under an effective confining pressure of $20 \mathrm{kPa}$. The effective stress $\sigma$ ' was maintained at around $20 \mathrm{kPa}$ at step two, and only excess pore water pressure $\mathrm{u}$ rose to around $80 \mathrm{kPa}$ as $\mathrm{B}$-value arranged in table 3 . After that, the velocities increase to $180 \mathrm{~m} / \mathrm{s} \sim 190 \mathrm{~m} / \mathrm{s}$ while the effective stress raised to 100 $\mathrm{kPa}$ after the excess pore water pressure release.

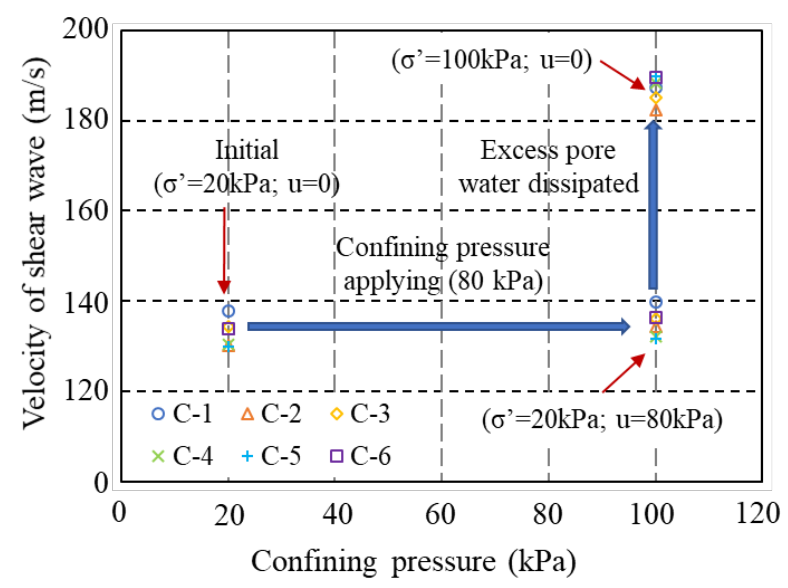

Fig. 8. Variation of small shear wave velocity during B-value checking

Besides, the excess pore water pressure increased gradually with the liquefaction potential increasing during cyclic test process in first and second liquefaction stages. The Vs checked by each 5 10 load cycles to investigate the continual varying process. Fig. 9 and Fig. 11. shows the results of Vs varies to the variation of effective stress during cyclic test process. The initial Vs of around 190 $\mathrm{m} / \mathrm{s}$ measured in the end of consolidation and reconsolidation just before cyclic tests was very similar as the value checked in the of B-value measurement. The outcomes supported the dependency from effective stress rather than the potential changes anisotropy cause by the shape's deformation and shear history.

In the first tests stage, the velocities decreased together with the effective stress until the effective stress reached 


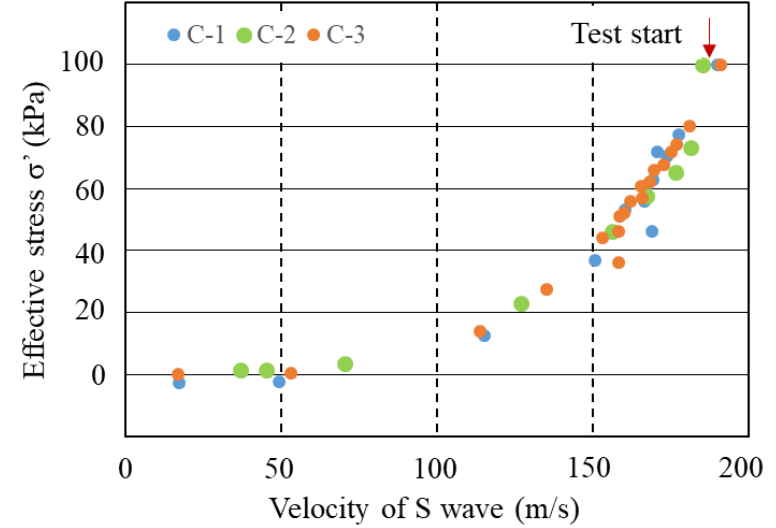

(a) Initial relative density $55 \% \sim 60 \%$

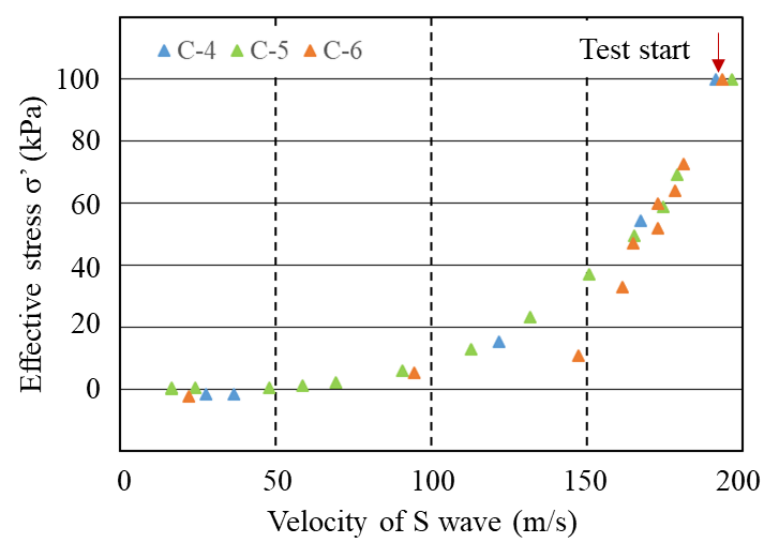

(b) Initial relative density $65 \% \sim 70 \%$

Fig. 9. Velocity variation of shear wave corresponding to effective stress during first liquefaction tests

zero. At this moment, all the velocities reduced to around $100 \mathrm{~m} / \mathrm{s}$. After that, shear wave velocity was found to be unstable after onset of liquefaction until $\mathrm{DA}=5 \%$ IS achieved, and continued decreasing, while the effective stresses maintained at a very low level nearby zero. The final value of the Vs was measured about $25 \mathrm{~m} / \mathrm{s}$ while DA $=5 \%$. There is not a clear interpretation for this result which was perhaps affected by the increase of accumulated anisotropy. This point is worth to be taken into consideration in the future study. The Vs plotted in Fig. 10., carried out the points without the affects from effective stress $(\mathrm{Vs}<100 \mathrm{~m} / \mathrm{s})$. The variations of the most points present a linear trend. The gradients $\Delta \sigma^{\prime} / \Delta \mathrm{Vs}$ of the linear trends in each case were arranged at Table 4 . It is found that most of them are very closed to 1.0 except C-4. According to the results, the varying process could be interpreted as that the effective decreases with a little faster rate than shear wave velocity until it loses about the half value from the initial state while the effective stress approaches to zero.

Variation of the Vs with effective stress during reliquefaction tests was plotted in Fig. 11. However, the excess pore water pressure generated rapidly, that leaded to lack of measured Vs to represent the continual variation between the range of $100 \mathrm{~m} / \mathrm{s} \sim 200 \mathrm{~m} / \mathrm{s}$. But still, the results could indicate that the effective stress decreased to very low level while Vs reduced to around $100 \mathrm{~m} / \mathrm{s}$.

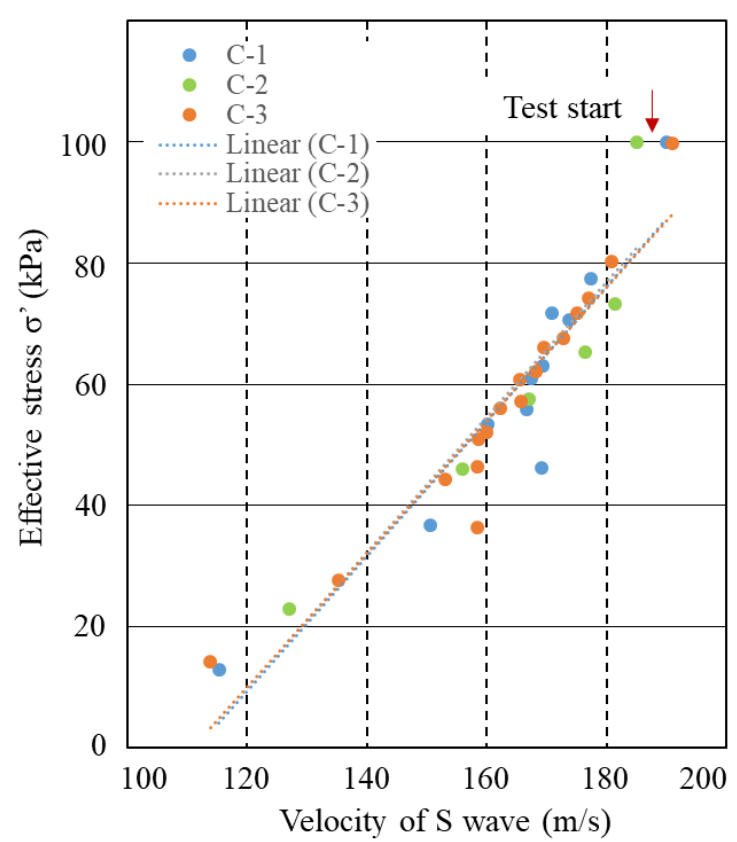

(a) Initial relative density $55 \% \sim 60 \%$

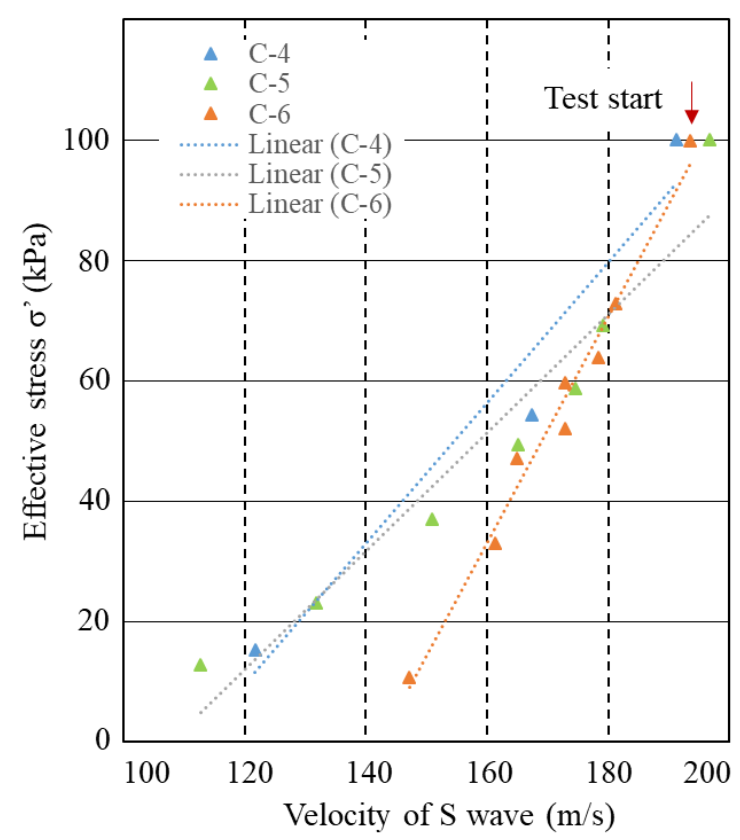

(b) Initial relative density $65 \% \sim 70 \%$

Fig. 10. Velocity variation of shear wave corresponding to effective stress during first liquefaction tests carried out the value less than $100 \mathrm{~m} / \mathrm{s}$

Table 4. Gradient of the trend line for velocity variation of shear wave carried out the value less than $100 \mathrm{~m} / \mathrm{s}$

\begin{tabular}{ccccccc}
\hline No. & C-1 & C-2 & C-3 & C-4 & C-5 & C-6 \\
\hline Gradient & 1.11 & 1.1 & 1.12 & 1.17 & 0.98 & 1.88 \\
\hline
\end{tabular}




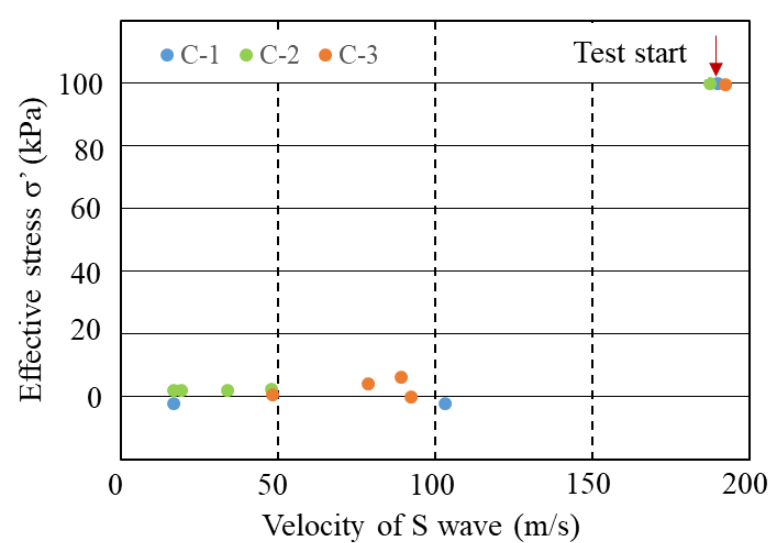

(a) Initial relative density $55 \% \sim 60 \%$

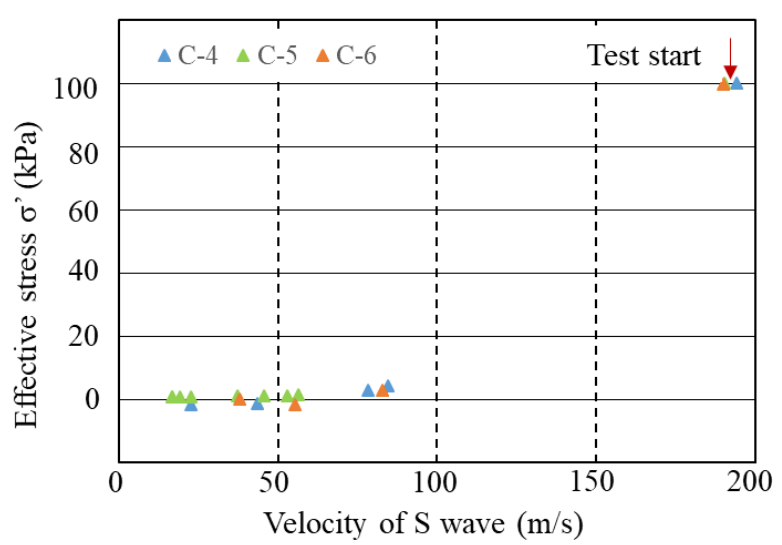

(b) Initial relative density $65 \% \sim 70 \%$

Fig. 11. Velocity variation of shear wave corresponding to effective stress during re-liquefaction tests

\section{Conclusions}

Utilizing improved cyclic tri-axial compression apparatus assembled with bender elements, six specimens made by Toyoura sand were tested in this study. According to the disaster situations caused by two great shocks in the 2016 earthquakes, Vs was discussed as a new indicator of the liquefaction potential for earthquake-affected soil. The produced excess pore pressure greatly affected the current liquefaction potential. Meanwhile, the changes of potential anisotropy also were regarded which affects liquefaction resistance significantly in re-liquefaction stages. Therefore, the correlation between Vs and the most portable determining factors were investigated. The results showed mainly as:

1) The Vs measured after consolidation and reconsolidation was very similar about $190 \mathrm{~m} / \mathrm{s}$. Therefore, Vs could not clearly reflect the significant reduction in resistance at re-liquefaction stages affected by the changes of anisotropy.

2) Vs of around $190 \mathrm{~m} / \mathrm{s}$ perhaps is the typical velocity at the effective stress of $100 \mathrm{kPa}$ for sandy soil.
3) Effective stress could be considered as the most important factor for determining Vs. The specific value $\Delta \sigma^{\prime} / \Delta \mathrm{Vs}$ is very closed to 1.0 . The effective decreases with a little faster rate than shear wave velocity until it loses about the half value to around $100 \mathrm{~m} / \mathrm{s}$ when the effective stress approaches to zero and to around $25 \mathrm{~m} / \mathrm{s}$ when the double amplitude reaches to $5 \%$.

4) Though the excess pore water pressure raised too fast in second stage, the results also could indicate that the effective stress decreased to very low level while Vs reduced to around $100 \mathrm{~m} / \mathrm{s}$.

The correlation between Vs and excess pore water pressure represent a regularity using the laboratorial results. However, there are still two unneglectable points that: 1) how to evaluate the current liquefaction potential from the excess pore water pressure produced currently; 2) how to estimate the Vs quantitatively with the changes of pre-and -post excess pore water to reflect the changes of current liquefaction potential. These issues have to take in account in the further study.

The authors are particular grateful for the contribution given by Mr. Nakashima who is the lab technician of Kyushu University.

\section{References}

1. JMA, http://www.data.jma.go.jp/svd/eqev/data/higai/higai 1996-new.html (In Japanese)

2. S. Murakami, H. Nagase, S. O-sato, H. Yakabe, Reports of geologic disasters in H28 Kumamoto Earthquakes, 5 (JGS, 2017) (In Japanese)

3. F Tatsuoka, K Ishihara, Soils Found. JGS 14, 2 (1974)

4. K Ishihara, F Tatsuoka, S Yasuda, Soils Found. JGS 15, 1 (1975)

5. K. Ishihara, S. Okada, Soils Found. JGS 18, 4 (1978)

6. S. Yamada, T. Takamori, K. Sato, Soils Found. JGS 50, 1 (2010)

7. B. Ye, J.F. Lu, G.L. Ye, Soil Dyn. Earthq. Eng. 77, 15-23 (2015)

8. R. Dobry, K. H. Stokoe II, R. S. Ladd, T. L. Youd, Proc., In Situ Tests to Evaluate Liquefaction Susceptibility, ASCE, New York. (1981)

9. K. Tokimatsu, T. Yamazako, Yoshimi, Y. Soils Found., JGS 26, 1 (1986)

10. R.D. Andrus, K.H. Stokoe II, J. Geotech. Geoenviron. Eng. 126, 11 (2000)

11. C. D. P. Baxter, A. S. Bradshaw, R. A. Green, J.H. Wang, J. Geotech. Geoenviron. Eng., 134, 1 (2008)

12. JGS 0544: (2011) (In Japanese) 